\title{
RESIDENTIAL QUALITY ASSESSMENT OF MULTI-STORY BUILDINGS THROUGH RESIDENCE EXPERIENCE: A CASE OF HYDERABAD, PAKISTAN
}

\author{
Mohammad Ali* \\ Hassam Bin Waseem ** \\ Mir Aftab Hussain Talpur*** \\ Rija Shakir**** \\ Jawad Akbar Jamali*****
}

\begin{abstract}
In this modern era, multi-story housing is conceived as a sustainable and land-saving solution to increasing housing demand. In developing countries like Pakistan, unplanned and unsustainable multi-story housing development in major cities like Hyderabad. Housing quality is getting worse day by day, creating a negative impact on the physical and social well-being of inhabitants. The study identified the factors which are making a negative impact on multi-story housing quality. The research is based on a thorough literature review, variables which helped categorize into safety and security, environment, life convenience, space utilization, utilities and services. To record the residents' opinion, the variables were inserted in a structured questionnaire with a 4-point Likert scale. Systematic sampling was applied to select a random sample of sixty buildings with an interval of 5 . Using multiple regression analysis, four variables, including outdoor noise, fire protection, lack of elevator facility and drainage, were found to have a negative impact. The study is significant as the results can be considered as a guide for planning and development agencies to improve the multistory housing quality by ensuring the inclusion of influential variables in the present and future development of multistory buildings.
\end{abstract}

Keywords: Housing Quality, Multi-Story Buildings, Quality of Life, Multiple Regression, Pakistan.

\section{INTRODUCTION}

Multi-story housing is currently recognized as a global phenomenon (Je, et. al., 200) Multi-Story housing was on a decline in the mid-1970s but now most policymakers, architects, planners and designers around the world have reaccepted multi-story housing as the most compact housing form (Olotuah, 200). Many investors believe that multistory housing is more efficient form of housing as compared to other residential types and has many benefits, such as less land consumption, higher energy efficiency and lower resource consumption (Kenn edy and Miller 2015). Housing quality of multi-story buildings is essential as it provides a peaceful environment to the inhabitants (Mat, et. al., 2013). It was found that housing quality is primarily based on the household income level as high income usually leads to a higher quality of housing (Chen Guang, et, al,. 2012). Since housing quality does not depend only on the internal characteristics of the housing units, there are some other external factors (say, community's surrounding environment, livability, walkability.) that are responsible for making the housing quality better. Hence, consideration of both aspects is important (Othuman, et. al., 2014). However, many researchers conclude that sustainable multistory housing involves the provision of infrastructural services that could bring about sustainable growth and development through improved environmental conditions and livelihood. In evaluating the quality of residential

\footnotetext{
* $\quad$ Mohammad Ali,

Email Correspondence: alikkoffical@gmail.com

** Hassam Bin Waseem, Department of City and Regional Planning, Mehran University of Engineering and Technology, Jamshoro, Pakistan Email correspondence: hassam.waseem@gmail.com

$* * * \quad$ Dr. Mir Aftab Hussain Talpur,

Email Correspondence: aftab.talpur@faculty.muet.edu.pk

$* * * * \quad$ Ms. Rija Shakir,

Email Correspondence: rija.shakir@yahoo.com

$* * * * * \quad$ Jawad Akbar Jamali,

Email Correspondence: jawad.akbar786@gmail.com
} 
development, human, infrastructural and environmental characteristics are core determinants of how residents interpret the housing quality (Othuman, et. al., 2014). Moreover, the literature review revealed that the perception of housing quality by residents is usually recorded as weak, if the buildings lack basic amenities that make housing unfit for inhabitants (Mat et. al., 2013).

In Pakistan, multi-story housing remains a controversial housing form. One of the focus of debates is on its quality issues (Rashid, et. al., 201). Many researchers claim that quality problems were the key reasons people avoided living there (Haghi, et. al., 2018). Evidence from the literature illustrated several variables that can be used in determining the housing quality in developing countries, such as Pakistan. Variables include: adequate privacy and space, security, environment (such as proper lighting, heating, and ventilation) and utility services (such as water supply, electricity, and gas (Brkaniae, 2017).

This study aimes to identify the factors which are creating a negative impact on multi-story housing quality in Hyderabad, Pakistan. The literature suggests statistical modeling as the critical analysis tool, using multiple linear regression is the optimum method. Hence, it was applied to construct statistical models for each category of variables for the cases documented.

\section{LITERATURE REVIEW}

Housing quality is one of the primary criteria in assessing quality of life and it is evaluated along other paradigms of street quality criteria, visual and noise quality for the assessment of environmental quality. From the viewpoint of urbanism, buildings should be constructed on the ideal and most healthy urban areas. In a subjective perspective, lodging should meet the self-related demands, needs and should provide the occupants with the spiritual social and hygienic and serene qualities (Chenguang, et. al., 2012). Based on the results of research by kurian and thampuran (2011) the order of importance of seven components in the quality of the housing is as followes: construction material and methods, security and safety, environment, space utilization infrastructures design, and life convenience. Several studies were found from the literature that assessed the multi-story housing quality. A study of subtropical Brisbane assessed the factors which are creating a negative impact on multi-story housing quality (Kennedy and Millen, 2015). Privacy was found as the most important factor and its absence could negatively impact housing quality. While discussing multi-story housing quality in Tianjin, China, a study found that environment was a factor having negative impact on multi-story housing quality (Chenguang et.al., 2012). While analyzing the factors having a negative impact on multi-story housing quality, a study in Tehran, Iran, found the quality of physical aspects as the most influential factor. Hence, it emphasized enhancing the condition of physical aspects to improve the overall multi-story housing quality (Haghi, et. al., 2018). A study conducted in Pakistan found utilities and services and the surrounding environment as the two main factors which are negatively impacting multi-story housing quality (Rashid et. al., 201). It is evident in the literative review that multi-story housing quality is a phenomenon that cannot be generalized (Chatterjee, 2009). It varies from country to country, even within cities of a country, depending upon the physical, socioeconomic and environmental aspects. Thus, for every urban area, an evaluation of multi-story housing quality is the need of time.

A study in Korea evaluated the factors affecting the housing quality of apartments (Yim, et. al, 2011). This study conducted questionnaire survey to record the response of apartment's residents. The study covers fourty seven apartments units which were selected by using systematic sampling. From each building one resident participated. The answers were rated using 4 point Likert scale. The collected data was analyzed through linear regression to identify the impact of housing quality factors. The study found space utilization and life convenience as the core determinants to decrease the quality of the apartments.

Regression models with one dependent variable and more than one independent variables are called multiple linear regression or multilinear regression (uyanyk and Guller, 2013). It is a statistical technique for estimating the relationship among variables, which have reason and result relation, and make prediction for the topic by using the relation. As the approach was adopted by various authors (Rashid, et. al., 201, Yim, et. al., 2011) to determine the impacts using a regression model; the approach was also used in this study.

The findings of the study revealed that no country in the world is devoid of the housing problem. Though, the situation is controlled in cities of developed countries, but the impacts of rapid urbanization and slow urban planning process in major third world cities like Hyderabad, Pakistan, makes the housing quality questionable (Haghi, et. al., 2018). As a result, multi-story housing quality is getting worse, which creates a negative impact on urban areas (Brkaniae, 2017). The problem further leads to the expansion of other 
problematic conditions, such as poor indoor environment, lack of ventilation, inadequate lighting, inadequate basic facilities (like electricity, gas and water) poor maintenance, absence of security and safety.

\section{RESEARCH DESIGN}

\section{Study Area}

For this study, Hyderabad city Taluka was selected. It is an administrative subdivision of the Hyderabad District located in Sindh, Pakistan. It covers an area of 20.37 square kilometers, with a population of 75,960. In Hyderabad city Taluka, multi-story housing is the most common housing form and is considered as of inferior quality, among other housing types. The vertical development is mostly driven by private developers who ignore almost all aspects of building design. Hence, the buildings fail to deliver a quality lifestyle to the inhabitants. Additionally, the problem has been compounded by the rapid rates of population and economic growth. Despite all these, neither effort has been made to address the issues of multi-story housing, nor have the factors having a negative influence on multi story housing quality been identified. Therefore, this research fills the gap by identifying the factors that are negatively impacting on multi-story housing quality in Hyderabad city Taluka.

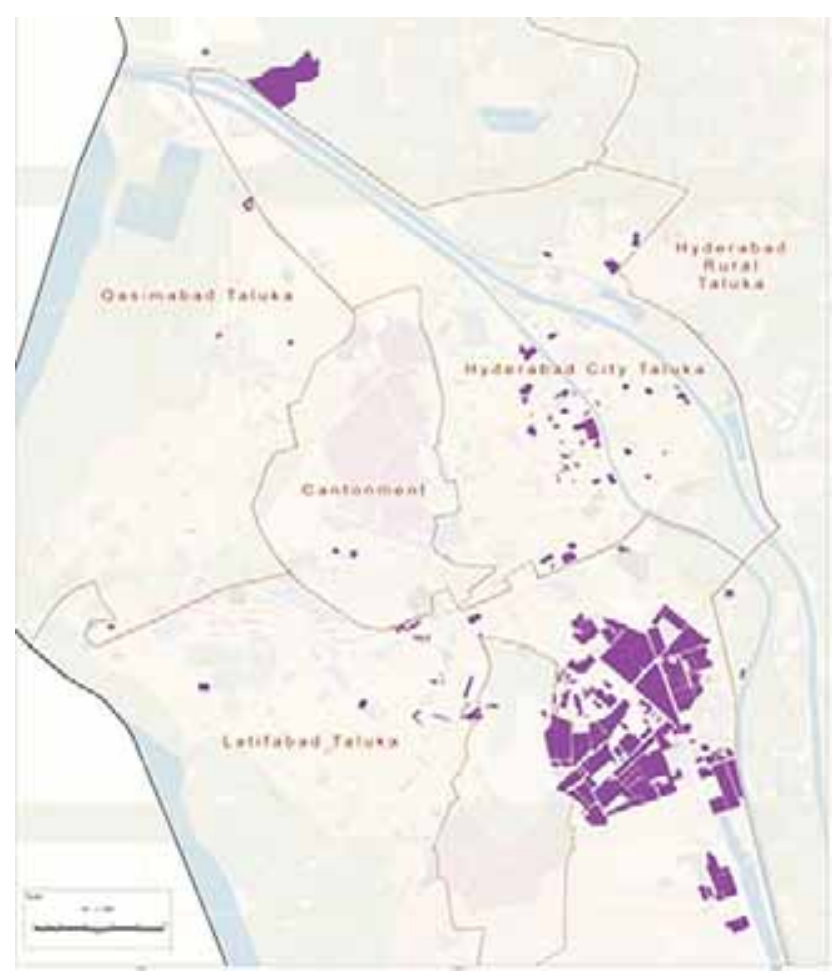

Figure-1: Hyderabad District Map.

\section{Research Methodology}

The methodology for this research is a mixture of site observation and questionnaire survey (Othuman, et. al., 2014). To collect the data a questionnaire survey method was adopted (Rashid et. al., 201). Based on predefined factors of housing quality, the questionnaire was designed accordingly. The responses were rated using a 4-point Likert scale so that the level of responsibility of factors could be measured (Haghi, et. al., 2018). Due to lack of time and resources, systematic sampling was used to cover the whole area. The first building was randomly selected and the next building was selected with an interval of 5 (Yim, et. al., 2011). After collection of data, analytical techniques of frequency distribution and statistical modelling (Multiple Linear Regression) were used to extract the required results. The reason for selecting multiple regression was to quantify the impacts of factors affecting multi-story housing quality (Rashid, et. al., 2017).

\section{Sampling Plan}

To construct a sampl plan the published literature was studied to select the suitable method for data collection and for selecting an accurate sample size. For this study, buildings having four stories $(\mathrm{G}+3)$ and above were selected for the survey (Chaltegee, 2009). Following the literature, systematic sampling was used to collect data. Out of two hundred and ninty registered multi-story buildings, sixty buildings were surveyed and studied. From each building one resident participated to record response. Hence a total sixty residents participated in questionnaire survey as described in Table 1.

\section{Theoretical Framework}

To have an inventory of variables to evaluate multi-story housing quality, a literature review was performed. As a result, several variables were identified that could assess multi-story housing based on the perception of residents. These variables are recognized worldwide and have been used by many authors to examine the multi-story housing quality. The study comprises of 1 dependent variable, i.e. multi-story housing quality, and independent variables categorized into 5 categories, i.e. life convenience (adequacy of parking, adequacy of elevator, and stairs), environment (air circulation, outdoor noise, sunlight, and temperature), security and safety (emergency exit, adequacy of fire protection system, and privacy), utilities and services (electricity, gas, water supply, and drainage), and space utilization (size of room, and open space). These variables 
Table-1: Sampling Plan.

\begin{tabular}{|c|c|c|c|}
\hline Study Area & $\begin{array}{c}\text { Total } \\
\text { Buildings }\end{array}$ & $\begin{array}{c}\text { Sample } \\
\text { Size } \\
(\mathbf{n}=5)\end{array}$ & $\begin{array}{c}\text { Resident } \\
\text { Participate } \\
\text { from Each } \\
\text { Building }\end{array}$ \\
\hline Hyderabad City Taluka & 290 & 60 & 1 \\
\hline
\end{tabular}

were inserted in a structured questionnaire with a 4-point Likert scale so that the household perception could be recorded. Then, the data was analyzed using multiple linear regression.

\section{RESULTS AND DISCUSSION}

\section{Environment}

Table 2 demonstrates the model summary and parameter estimates for environmental factors. A value of 0.702 for ' $R$ ' indicates that the environmental factors have a significant impact on housing quality on multi-story buildings. A value of 0.493 for ' $\mathrm{R} 2$ ' depicts that the predictors lie close to the regression line, i.e., a good level of prediction. A value of 0.453 for 'Adjusted R2' reveals that $45.3 \%$ of residents recognize that environmental factors have a significant impact on housing quality. Whereas, outdoor noise was found to have a negative impact of multi-story housing quality with values of -0.431 , respectively.

\section{Security and Safety}

Table 3 illustrates the model summary and parameter estimates for security and safety. A value of 0.806 for ' $R$ ' indicates that the security and safety factors are considered as vital factors by inhabitants to decide about the quality of a house. It is evident that everyone wants a secure and safe house. Without security and safety, people feel discomfort that consequently decreases housing quality. A value of 0.650 for 'R2' depicts that the predictors lie close to the regression line, i.e. a good level of prediction. A value of 0.629 for 'Adjusted R2' reveals that $62.9 \%$ of people consider security and safety as an important factor while selecting a house. Whereas, black of proper fire protection ststem was found as the only factor having a negative impact on multi-

Table-3: Regression Coefficients for Security and Safety Variables.

\begin{tabular}{|c|l|c|c|c|c|}
\hline S. No. & Factor & Beta & Std Error & t & Sig \\
\hline & Constant & 2.444 & 0.342 & 7.145 & 0.000 \\
\hline X5 & Emergency Exits & 0.184 & 0.097 & 0.871 & 0.388 \\
\hline X6 & Fire Protection & -0.451 & 0.111 & -3.550 & 0.000 \\
\hline X7 & Privacy & 0.549 & 0.118 & 6.627 & 0.000 \\
\hline
\end{tabular}

Table-2: Regression Coefficients for Environment Variables.

\begin{tabular}{|c|l|l|c|c|c|}
\hline S. No. & Factor & Beta & Std Error & t & Sig \\
\hline & Constant & 2.530 & 0.509 & 4.96 & 0.000 \\
\hline X1 & Air Circulation & 0.84 & 0.097 & 0.871 & 0.388 \\
\hline X2 & Outdoor Noise & -0.431 & 0.111 & -3.871 & 0.000 \\
\hline X3 & Sun Light & 0.617 & 0.118 & 5.209 & 0.000 \\
\hline X4 & Temperature & 0.21 & 0.094 & 0.227 & 0.821 \\
\hline
\end{tabular}

story housing quality. Its absence makes tenants feel unsafe.

\section{Utilities and Services}

Table 4 illustrates the model summary of the utility services factor. A value of 0.809 for ' $R$ ' indicates that utility services factors have a significant impact on all housing quality factors. A value of 0.654 for 'R2' depicts that the predictors lie close to the regression line. A value of 0.627 for 'Adjusted R2' reveals that $62.7 \%$ of residents think that utility services have a significant impact on housing quality. Whereas, drainage was found as the factor having a negative influence with a coefficient value of -0.416 . This can be justified as Hyderabad city Taluka has experienced a marked increase in the residential density due to which the utility infrastructure has become overburdened. A utility line that was intended to serve a single-family unit is now serving a multi-story structure that accommodates more than fifty families.

\section{Life Convenience}

Table 5 demonstrates the model summary for life convenience. A value of 0.817 for ' $\mathrm{R}$ ' indicates that the life convenience factors have a significant role in decent quality of housing. A value of 0.668 for 'R2' depicts that the predictors lie critically close to the regression line, i.e., an excellent level of prediction. A value of 0.648 for 'Adjusted R2' reveals that $64.8 \%$ of poor quality of housing is due to lack of facilities needed to support the residents of a multi-story building. The absence elevator was found to have a negative impact as it was absent in $\mathrm{G}+3$ buildings of Hyderabad city.

Table-4: Regression Coefficients for Utilities and Services Variables.

\begin{tabular}{|l|l|c|c|c|c|}
\hline \multicolumn{6}{|l|}{$\mathrm{R}=0.809, \mathrm{R}^{2}=0.654$, Adjusted $\mathrm{R}^{2}=0.627$, Std. Error Estimate $=0.486214$} \\
\hline S. No. & Factor & Beta & Std Error & $\mathbf{t}$ & Sig \\
\hline & Constant & 2.908 & 0.430 & 6.756 & 0.000 \\
\hline X8 & Electricity & 0.001 & 0.075 & 0.018 & 0.986 \\
\hline X9 & Gas & 0.674 & 0.091 & 7.414 & 0.000 \\
\hline X10 & Water Supply & 0.124 & 0.086 & 1.439 & 0.156 \\
\hline X11 & Drainage & -0.416 & 0.075 & -5.583 & 0.000 \\
\hline
\end{tabular}




\section{Space Utilization}

Table 6 illustrates the model summary for space utilization. A value of 0.219 for ' $R$ ' indicates that the space utilization factors have less impact among all factors of housing quality in Hyderabad. A value of 0.48 for 'R2' depicts that the predictors are not outliers but lies away from the regression line, i.e., not a good level of prediction. A value of 0.116 for 'Adjusted R2' reveals that only $11 \%$ of the poor quality of housing is caused due to the space utilization factors. As the determination of the differences between actual and estimated variables is calculated through the 'standard error of the estimate', a value of 0.798180 illustrates that the difference between actual and estimated variables is quite high. Thus, what the model predicts is not accurate as of the real condition. The insignificance of this factor is because people are still unaware of the importance of open space and its utilization that leads to improper space management, which results in inefficient space utilization.

\section{DISCUSSION}

Considering the Beta $(\beta)$ and Sig $(p)$ values for the environment variables, that outdoor noise has a negative impact on multi-story housing quality. The problem is usually caused due to exposure to outside traffic noise, noise from adjacent apartments and noise from upper floors. Moreover, insulation is usually avoided in building construction. The effect is primarily psychological impacting productivity, general behavior, sleep disorders, and disturbance to conversations that affects the health and daily life of residents.

Among all security and safety variables, lack of fire protection facility had a negative impact on multi-story housing quality. Thus, it can be inferred that people are dissatisfied with their apartments in terms of fire protection facility. Due to a lack of awareness of the necessity of fire protection systems in buildings, the developers do not consider fire safety measures in building design. The situation is critical as its absence could have devastating consequences that might lead to loss of human lives and can cause respiratory problems among residents.

Among utilities and services, lack of adequate drainage had system a significant negative impact on multi-story housing quality. To meet the ever-increasing housing demand, construction of multi-story residential buildings on small size plots is a common practice that creates a burden on the infrastructure. This overburden leads to drainage and sanitation system failure and as a result, the pipelines leak or one choked and the sewerage water overflows on the streets and roads.

In terms of life convenience, lack of elevator facility is the most common element that is absent in multi-story buildings of Hyderabad city Taluka. The reason is lack of interest of developers regarding user comfort. To cut the cost of the building construction projects, the developers neglect provision of elevators and utilize that space into any other possible room/facility to earn more profits. The negligence of this facility causes mobility issues, especially for patients, disabled persons, and the elderly.

It is concluded that outdoor noise, lack of fire protection, poor drainage, and absence of elevators were the main factors having negative impact on the multi-story housing quality of Hyderabad city Taluka.

\section{CONCLUSION}

In the last decade, many policymakers, architects, planners and designers around the world have accepted multi-story housing as the most optimum housing type to accommodate the increase in urban population. But due to poor planning and inefficient zoning in third world cities like Hyderabad, the solution has been converted into malaise, as multi-story buildings lack basic elements like safety and security, adequate livable environment and utilities and

Table-5: Regression Coefficients for Life Convenience Variables.

\begin{tabular}{|c|l|c|c|c|c|}
\hline $\mathrm{R}=0.871, \mathrm{R}^{2}=0.667$, Adjusted $\mathrm{R}^{2}=0.648$, Std. Error Estimate $=0.46359$ \\
\hline S. No. & Factor & Beta & Std Error & $\mathbf{t}$ & Sig \\
\hline & Constant & 2.297 & 0.342 & 6.709 & 0.000 \\
\hline $\mathrm{X} 12$ & Parking Space & 0.251 & 0.064 & 3.929 & 0.000 \\
\hline $\mathrm{X} 13$ & Elevator & -0.485 & 0.077 & -6.327 & 0.000 \\
\hline $\mathrm{X} 14$ & Stair & 0.556 & 0.084 & 6.585 & 0.000 \\
\hline
\end{tabular}

Table-6: Regression Coefficients for Space Utilization Variables.

\begin{tabular}{|c|l|c|c|c|c|}
\hline \multicolumn{6}{|l|}{$\mathrm{R}=0.219, \mathrm{R}^{2}=0.048$, Adjusted $\mathrm{R}^{2}=0.11$, Std. Error Estimate $=0.798180$} \\
\hline S. No. & Factor & Beta & Std Error & t & Sig \\
\hline & Constant & 2.885 & 0.282 & 10.109 & 0.000 \\
\hline X15 & Size of Room & -0.213 & 0.431 & -0.493 & 0.624 \\
\hline X16 & Open Space & -0.392 & 0.403 & 0.974 & 0.335 \\
\hline
\end{tabular}


services. Based on the results, it was found that four significant factors had a negative impact on multi-story housing quality, i.e., outdoor noise, lack of adequate fire protection, poor drainage and absence of elevators. Hence, several measures are required on the aforementioned variables to improve the multi-story housing quality in Hyderabad city. The results of the study provided a foundation for improving the overall housing quality of multi-story buildings.

\section{ACKNOWLEDGMENT}

I, Muhammad Ali would like to express special thanks to coauthors who helped to complete this paper and provided the opportunity to learn many new things. I am really thankful to them.

\section{REFERENCES}

Brkaniae, I., 2017, “Housing Quality Assessment Criteria”, Elektronieki Easopis Gradevinskog Fakulteta Osijek, $37-47$.

Chatterjee, M, 2009, "Perception of Housing Environment Among Hight Rise Dwellers", Journal of the Indian Academy of Applied Psychology, 35(Special 1).

Chenguang, Li, Lu, Sun, Jones, P., 2012, “ Liveability of High-Rise Housing Estates: A Resident Centered Hight-Rise Residential Environment Evaluation in Tranjin, China”, 48th ISOCARP Congress.

Haghi, M. R., Samavati, S., Eskandari, A., 2018, “An Evaluation of Housing Quality in Two Types of Conventional Housing Vs. Apartments: Case Study: Haft Hoz Neighborhood and the 1st Phase of Ekbatan Community in Tehran”, Space Ontology International Journal, 7(2): 23-24.

Je, H, Lee, J, Cheong S, Shin, S-W, 2007, “A Study on Residential Quality Index of Super High-Rise Apartment Housing through Survey with Experts”, Proceedings of the International Conference on Sustainbale Building Asia, 27-29 June 2007, Seoul, Korea in House Publishing.

Kennedy, R., Buys, L., Miller, E., 2015, “Residents' Experiences of Privacy and Comfort in Multi-Storey Apartment Dwellings in Subtropical Brisbane", Sustanability, 7(6): 7741-61.

Kurian, S. M., Thampuran, A., 2011, “Assessment of Houding Quality: Institute of Town Planners”, India Journal, (2):7485.

Mat, Noor, N., Eves, C., A. Mutalibun, 2013, "High Rise Residential Building Quality: Residents Satisfaction Survey", In: Manley K., Kajewski S, (eds), Proceedings of the 19th International CIB World Building Congress, Brisbane Construction and Society, Australia: Queensland University of Technology, P. 1-10.

Olotuah, AO, 2007, "Housing Quaity in Suburban Areas (An Empirical Study of Oba-Ile, Nigeria)", Journal of Architecture and Built Environment, 34.

Othuman, M., Mohamed MF., Raman S. N., Iman P. T. M., Mohammad Y., Che A., 2014, “Outdoor Environment of LowCost Housing: A Case Study of Flat Taman Desa Sentosa", E3S Web of Conferences.

Rashid, J., Hussain, I., Syed S., 2017, "Insight of the Quality of Housing of Pakistan Households: Using New Methodology and the Countrywide Unit Record Data” Forman Journal of Economic Studies, 00:121-33.

Uyanyk, G. K. Guler, N., 2013, “A Study on Multiple Linear Regression Analysis”, Procedia-Soc Behav sci, 106:234-40.

Yim, H. L., Lee, B. H., Kim, J. H., Kim, J. J., 2011, “The Effect of the Quaity of Apartment Houses on the Residentail Satisfaction nd Corporation Performance", Proc 28th Int Symp Autom Robot Constr ISARC, $1394-400$. 